\title{
INHERITANCE OF LONG AND DENSE CAPSULE CHARACTERISTICS IN SESAME
}

\author{
Engin YOL, Cengiz TOKER, Bülent UZUN* \\ Akdeniz University, Faculty of Agriculture, Department of Field Crops, Antalya, TURKEY \\ *Corresponding author: bulentuzun@akdeniz.edu.tr
}

Received: 30.09.2016

\begin{abstract}
Long and dense capsule characteristics in sesame (Sesamum indicum L.) are associated with high seed yield. Therefore, inheritance of long and dense capsule and their genetic association were investigated in a cross of "Muganli-57 ( + )" with short and sparse capsule with "ACS 352 ( )" having long and dense capsule. In the F , long and dense capsule characteristics were dominant over short and sparse capsules. In the $F_{2}, 12: 3: 1$ segregation ratio revealed that long capsule character had dominance with epistasis over dense capsule. The presence of the dominant $L n$ allele (long capsule) masked the effects of either $D n$ or $d n$ alleles (dense capsule). The expected 12:3:1 segregation ratio in $F_{2}$ was confirmed in $F_{3}$. The results suggested that positive selection for long and dense capsule characteristics in sesame should be given high priority to reach ideal plant type with high seed yield potential.
\end{abstract}

Keywords: Capsule length, capsule density, epistasis, genetics, Sesamum indicum L.

\section{INTRODUCTION}

Sesame (Sesamum indicum L.) is one of the most important oilseed crops with high oil content, protein and several unique antioxidants (Arslan et al. 2007; Uzun et al. 2007; 2008; Erbas et al. 2009; Yol et al. 2013). It was grown on 10.5 million ha for total production of 5.4 million $\mathrm{t}$ with an average yield of $517 \mathrm{~kg} / \mathrm{ha}$ (FAOSTAT 2014). Sesame has valuable agricultural characteristics since it can be grown on residual soil moisture without supplemental irrigation (Ashri 2007), and suitable for second crop production (Sogut 2009). Despite the advantages, its production falls behind the major oilseed crops since seed yield of the crop is relatively low and instable. Therefore, breeding efforts have mainly focused on increasing seed yield directly or indirectly through yield related characteristics (Ashri 1989; El-Bramawy and Shaban 2008; Furat and Uzun 2010). Number of capsule per plant is one of the most used selection criteria in sesame breeding (Subramanian and Subramanian 1994; Baydar 2005; Gnanasekaran et al. 2008; Yol et al. 2010; Yol and Uzun 2012). Long and dense capsule characteristics have a great impact on seed yield in sesame by enabling plants to produce more capsules and seeds (Bisht et al. 2004; Sarwar et al. 2007). This relation was exhibited by Chowdhury et al. (2010) and Ogbanna and Ukaan (2012) obtained positive correlation between seed yield and longer capsule in sesame. Increase in number of pods per plant and capsule length contributing seed yield, positively has also been observed in different crops such as rapeseed (Ozer et al. 1999) cajanus (Udensi and Ikpeme 2012) and cowpea (Aliyu and Makinde 2016). The basic requirement in a suitable breeding method is based on understanding of the genetic behavior of desirable characteristics (Sumathi and Muralidharan 2009). According to available literature, neither genetics of long capsule nor dense capsule characteristics in sesame have been studied so far. Therefore the objective of this article was to study the inheritance of long and dense capsule in sesame.

\section{MATERIALS AND METHODS}

\section{Experimental site and agronomic applications}

The experiments were conducted at the fields of the West Mediterranean Agricultural Research Institute, Antalya $\left(36^{\circ} 52^{\prime} \mathrm{N} .30^{\circ} 50^{\prime} \mathrm{E}\right.$. $15 \mathrm{~m}$ elevation), Turkey. The parents and the offsprings were sown silt and clay soil type with $\mathrm{pH}$ of 7.8. Fertilizer was applied at the rate of 60 $\mathrm{kg}$ nitrogen $(\mathrm{N}), 60 \mathrm{~kg}$ phosphorus $\left(\mathrm{P}_{2} \mathrm{O}_{5}\right)$ and $60 \mathrm{~kg}$ potassium $\left(\mathrm{K}_{2} \mathrm{O}\right)$ per hectare prior to sowing. Planting was done at the end of May in all the growing years. The residues were removed before sowing, and then seed bed was watered by furrow irrigation for soil moisturizing. The experimental area has typically Mediterranean climate type which is characterized by dry summers, very limited rainfall during summers and about $60 \%$ humidity. 


\section{Parents and progenies}

Capsule length varied from 1.3 to $7.0 \mathrm{~cm}$ with average length of about $2.5 \mathrm{~cm}$ in sesame (Langham and Wiemers 2002), whereas number of capsule per plant ranged 2 to 76 per plant with the average of 19 (Mahajan et al. 2007). ACS 352 was selected for long and dense capsule with about $5.5 \mathrm{~cm}$ and 55 capsule per plant, respectively; while Muganli-57, the local registered cultivar, had short (about $3 \mathrm{~cm}$ ) and sparse capsule (36 capsule per plant) (Figure 1). ACS 352 was crossed with Muganli-57 in 2008. The crosses between Muganl1-57 (q) (short and sparse capsule) and ACS 352 (ठ゚) (long and dense capsule) were made using flower buds emasculated just before anthesis and pollinated the second day with pollen grains from freshly dehisced anthers of the male parents (Falusi and Salako 2003). The $F_{1}$ s were selfed in the growing season of 2009 and the $F_{2}$ and the $F_{3}$ populations were grown in two following years of 2010 and 2011.

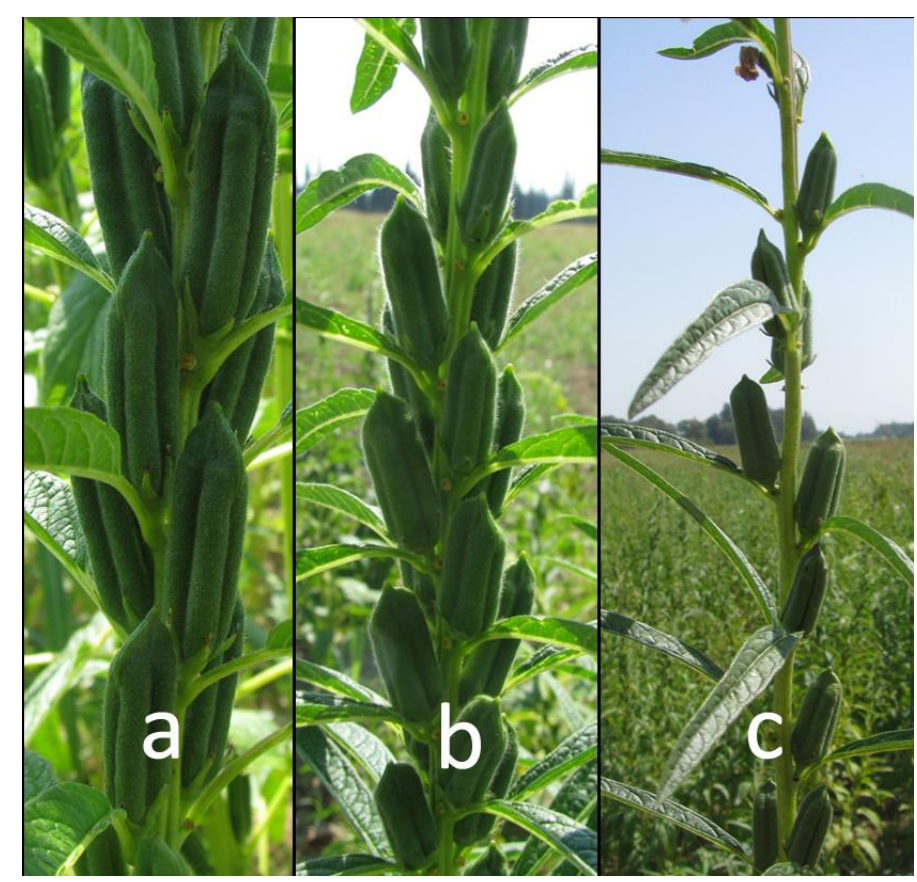

Figure 1. Different types of capsule length and density. a indicated high capsule length and density, b indicated normal capsule length and high capsule density, $\mathrm{c}$ indicated normal capsule length and density.

\section{Statistical analysis}

The chi-square $(\chi 2)$ goodness of fit test was performed on the $F_{2}$ population against a possible theoretical segregation ratio using the formula:

$$
\chi 2=\Sigma(\mathrm{Oi}-\mathrm{Ei})^{2} / \mathrm{Ei},
$$

where Oi and Ei are the observed and expected values, respectively (Steel and Torrie 1980).

In the $F_{3}$, long and dense capsule, short and dense capsule and short and sparse capsule types obtained from the $F_{2}$ plants were sown separately and possible theoretical segregation ratio was calculated according to the same formula.

\section{RESULTS}

$F_{1}$ progenies

All the plants derived from the cross between Muganli-57 and ACS 352 produced long and dense capsules indicating that long and dense capsule characteristics were dominant over short and sparse capsules.

\section{$F_{2}$ progenies}

The number of plants with long and dense capsule, short and dense capsule, and short and sparse capsule (Figure 1) in the $\mathrm{F}_{2}$ progenies was found as 55, 16 and 5 plants, respectively; while no plant with long and sparse capsule was observed. This segregation ratio showed a good fit for a $F_{2}$ phenotypic ratio of 12:3:1 according to Chi-Square Test (Table 1). 
Table 1. Observed and expected segregation ratios of long and dense capsule characteristics in $\mathrm{F}_{2}$

\begin{tabular}{|c|c|c|c|c|c|c|c|c|c|c|c|}
\hline Cross & \multicolumn{4}{|c|}{ Experimental observed } & \multicolumn{4}{|c|}{ Theoretical expected } & \multirow[t]{2}{*}{ Ratio } & \multirow[t]{2}{*}{$\chi^{2}$} & \multirow[t]{2}{*}{$\mathbf{P}$} \\
\hline $\begin{array}{c}\text { Muganli-57() } \\
\text { x } \\
\text { ACS } 352(\text { Љ) }\end{array}$ & 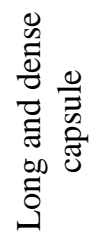 & 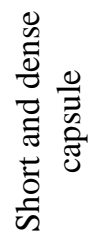 & 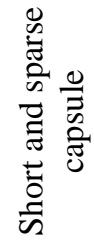 & 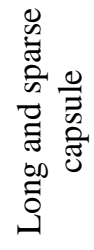 & 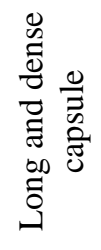 & 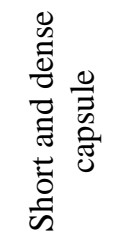 & 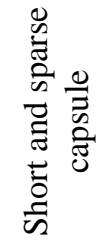 & 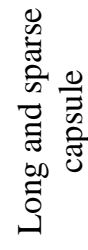 & & & \\
\hline & 55 & 16 & 5 & 0 & 57 & 14.25 & 4.75 & 0 & $12: 3: 1$ & 0.29 & $0.950-0.975$ \\
\hline
\end{tabular}

Table 2. $F_{2}$ progenies in $F_{3}$ generation for long and dense capsule characteristics

\begin{tabular}{|c|c|c|c|c|c|c|}
\hline \multirow{2}{*}{$\begin{array}{l}\text { Cross } \\
\text { Muganli-57 x ACS } 352\end{array}$} & \multirow{2}{*}{$\begin{array}{l}\text { Long and dense } \\
\text { capsule }\end{array}$} & \multirow{2}{*}{$\begin{array}{c}\text { Observed } \\
\begin{array}{l}\text { Short and dense } \\
\text { capsule }\end{array} \\
\end{array}$} & \multicolumn{3}{|c|}{ Expected } & \multirow[b]{2}{*}{ Gene Symbols } \\
\hline & & & $\begin{array}{c}\text { Short and sparse } \\
\text { capsule }\end{array}$ & Ratio & $\chi^{2}$ & \\
\hline \multicolumn{7}{|c|}{$\mathrm{F}_{2}$ progenies with long and dense capsule } \\
\hline Offspring 1 & 18 & 0 & 0 & 16:0:0 & $0.0^{\mathrm{ns}}$ & Ln-Dn- \\
\hline Offspring 2 & 15 & 0 & 0 & $16: 0: 0$ & $0.0^{\mathrm{ns}}$ & $L n-D n-$ \\
\hline Offspring 3 & 21 & 6 & 1 & $12: 3: 1$ & $0.62^{\mathrm{ns}}$ & LnlnDndn \\
\hline Offspring 4 & 11 & 0 & 0 & $16: 0: 0$ & $0.0^{\mathrm{ns}}$ & $L n-D n-$ \\
\hline Offspring 5 & 38 & 11 & 0 & $12: 3: 1$ & $0.17^{\mathrm{ns}}$ & $\operatorname{Ln} \ln D n D n$ \\
\hline Offspring 6 & 32 & 0 & 0 & 16:0:0 & $0.0^{\mathrm{ns}}$ & Ln-Dn- \\
\hline Offspring 7 & 10 & 0 & 0 & $16: 0: 0$ & $0.0^{\mathrm{ns}}$ & $L n-D n-$ \\
\hline Offspring 8 & 44 & 13 & 3 & $12: 3: 1$ & $0.44^{\mathrm{ns}}$ & $\operatorname{Ln} \ln D n d n$ \\
\hline Total & 189 & 30 & 4 & $12: 3: 1$ & & \\
\hline \multicolumn{7}{|c|}{$\mathrm{F}_{2}$ progenies with short and dense capsule } \\
\hline Offspring 1 & 0 & 20 & 0 & $0: 16: 0$ & $0.0^{\mathrm{ns}}$ & $\ln \ln D n-$ \\
\hline Offspring 2 & 0 & 15 & 4 & $0: 12: 4$ & $0.69^{\mathrm{ns}}$ & $\ln \ln D n d n$ \\
\hline Offspring 3 & 0 & 26 & 0 & $0: 16: 0$ & $0.0^{\mathrm{ns}}$ & $\ln \ln D n-$ \\
\hline Offspring 4 & 0 & 19 & 0 & $0: 16: 0$ & $0.0^{\mathrm{ns}}$ & $\ln \ln D n-$ \\
\hline Offspring 5 & 0 & 16 & 0 & $0: 16: 0$ & $0.0^{\mathrm{ns}}$ & $\ln \ln D n-$ \\
\hline Offspring 6 & 0 & 20 & 6 & $0: 12: 4$ & $0.05^{\mathrm{ns}}$ & $\ln \ln D n d n$ \\
\hline Total & 0 & 146 & 10 & $0: 12: 4$ & & \\
\hline \multicolumn{7}{|c|}{$F_{2}$ progenies with short and sparse capsule } \\
\hline Offspring 1 & 0 & 0 & 39 & $0: 0: 16$ & $0.0^{\mathrm{ns}}$ & $\ln \ln d n d n$ \\
\hline Offspring 2 & 0 & 0 & 20 & $0: 0: 16$ & $0.0^{\mathrm{ns}}$ & $\ln \ln d n d n$ \\
\hline Offspring 3 & 0 & 0 & 26 & $0: 0: 16$ & $0.0^{\mathrm{ns}}$ & $\ln \ln d n d n$ \\
\hline Offspring 4 & 0 & 0 & 9 & $0: 0: 16$ & $0.0^{\mathrm{ns}}$ & $\ln \ln d n d n$ \\
\hline Total & 0 & 0 & 108 & $0: 0: 16$ & & \\
\hline
\end{tabular}




\section{$F_{3}$ progenies}

The plants with long and dense capsule, short and dense capsule, and short and sparse capsule in the $F_{2}$ were individually advanced to the $\mathrm{F}_{3}$ generation by growing in single rows, separately. Segregations and their ratios of the offsprings in the $\mathrm{F}_{3}$ were given in Table 2 . In the $F_{2}$ progenies with long and dense capsule, the total number of offsprings with long and dense capsule, short and dense capsule and short and sparse capsule was found as 189, 30 and 4 , respectively. In the $F_{2}$ progenies with short and dense capsule, the total number of offsprings having short and dense capsule and short and sparse capsule was counted as, 146 and 10, respectively. $F_{2}$ progenies with short and sparse capsule produced only short and sparse capsule offsprings in the $\mathrm{F}_{3}$. Similarly in the offspring 8 , the same segregation pattern was observed with those numbers of 44, 13, and 3, respectively. These results indicated that long and dense capsule, short and dense capsule and short and sparse capsule plants fitted the expected 12:3:1 ratio in both offspring 3 and 8 (Table 2). It was evident that non-significant chi-square values were found when the dominant epistatic segregation hypothesis was tested for offsprings 3 and 8 .

Offsprings 2 and 6 sourced from $F_{2}$ plants with short and dense capsule consisted of 15 and 20 plants with short and dense capsule and 4 and 6 plants with short and sparse capsule, respectively. The non-significant chi-square values were found when the hypothesis of the dominant epistatic segregation was tested for offspring 2 and 6 . The other offsprings $(1,3,4$ and 5$)$ in the $F_{3}$ sourced from the $\mathrm{F}_{2}$ plants with short and dense capsule showed no segregation and had only the plants with the same characteristics (Table 2).

The offsprings in the $F_{3}$ coming from the $F_{2}$ plants with short and sparse capsule had no segregation and all the plants had short and dense capsule characteristics as in their parents.

\section{DISCUSSION}

Phenotypic observations in all the generations clearly demonstrated that long capsule in sesame had epistatic effect on dense capsule characteristic. Long and dense capsule characteristics were denoted with $l n$ and $d n$ gene symbols, respectively. Long capsule $(L n)$ was dominant over short capsule $(l n)$. Similarly, dense capsule $(D n)$ was dominant over sparse capsule $(d n)$. If long and dense capsule characteristics were independently controlled by single gene, the ratio of $F_{2}$ would be expected as 9:3:3:1.
However, epistatis did not allow this regular segregation due to dominance epistasis of long capsule on dense capsule.

To provide more reliable information that would be less subject to misinterpretation, $F_{2}$ plants were individually advanced to the $F_{3}$. In the $F_{2}$ progenies with long and dense capsule, the ratio of the total number of offsprings with long and dense capsule, short and dense capsule and short and sparse capsule were found to be fitted to 12:3:1 (Table 2). This type of interaction was identified as dominant epistasis. According to the $\mathrm{F}_{3}$ results from Table 2, the dominant long capsule allele $(L n)$ affected the expression of sparse capsule $(d n)$ displaying another phenotype, dense capsule $(D n)$. Expected ratios in the $F_{3}$ families with long capsule produced three different genotypic model as shown; Ln-Dn-, LnlnDndn and $L n \ln D n D n$. The offsprings in the $\mathrm{F}_{3}$ generation obtained from $\mathrm{F}_{2}$ progeny with short and dense capsule was also evident that no long and dense capsule types were observed. In addition, offsprings in the $F_{3}$ had only short and sparse capsule sourced from the $F_{2}$ progenies with short and sparse capsule (Table 2).

Bisht et al. (2004) stated that long capsule dominancy was interesting. When they crossed single stem type accessions (uniculm) with long capsule ones, segregating plants with desired traits such as long capsules with high seed density was generated. Differently, capsule length has been identified as neutral trait in determining seed yield by Ashri (1988). In the current study, long and dense capsule types could morphologically be distinguished since capsule length and number of capsule per plant were categorized into qualitative classes. Long and dense capsule characteristics could easily be distinguished from short and sparse capsule, and these characteristics were similar to long and short pea (Pisum sativum L.) in George Mendel's work (Strickberger 1985). A typical character of long capsule was of hollow line between locules comparing to their short counterparts (Figure 2). The hollow line between locules in long capsules could be observed in all the developmental stages of the capsule starting from capsule initiation to the harvest time. This pattern could be used as a morphological marker for determining the long capsules. Thus, long and dense capsule had rational inheritance and these two characteristics was under the control of Mendelian genetics. Similarly long capsule was assessed for qualitative characters in the studies conducted by Bisht et al. (1998) and Mahajan et al. (2007). 


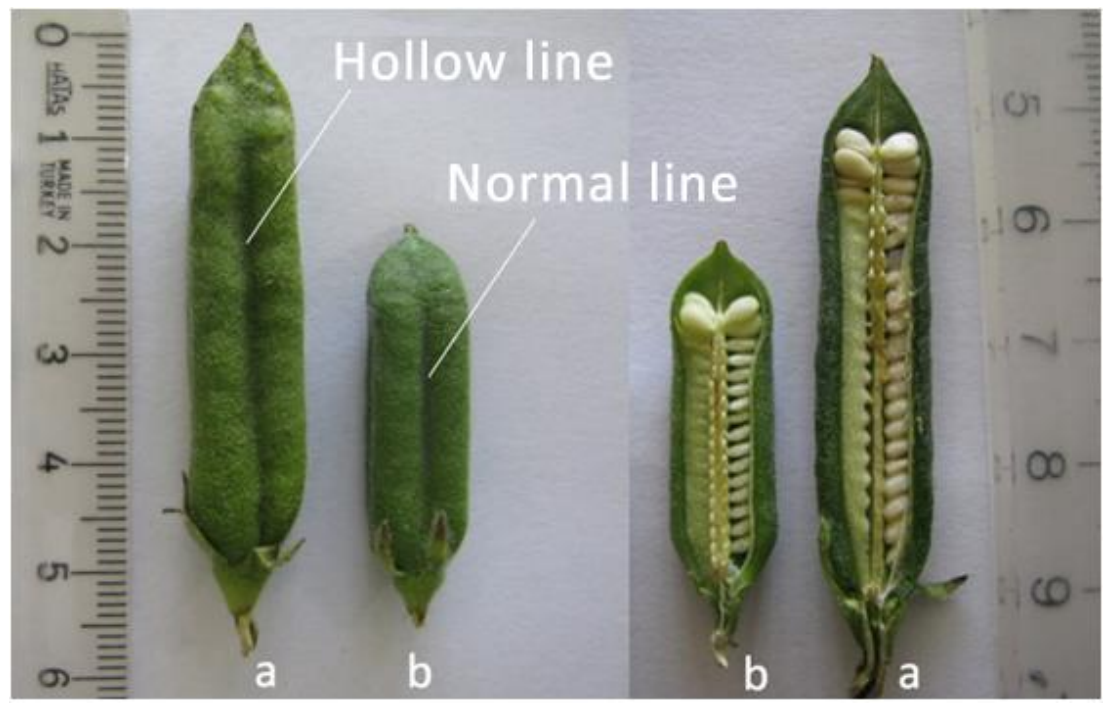

Figure 2. Morphological differences between normal and high length capsule. a is high length capsule, b is normal capsule.

The results of the study clearly showed that long and dense capsule characters were dominant over short and sparse capsule, respectively. Particularly, long capsule had dominant epistatic effect on dense capsule. The information about inheritance of long and dense capsule characteristics would highly be beneficial for genetic improvement of this neglected crop.

\section{ACKNOWLEDGEMENTS}

The authors are thankful to the Scientific Research Projects Coordination Unit of Akdeniz University and the Scientific and Technological Research Council of Turkey (TUBITAK) for their financial supports.

\section{LITERATURE CITED}

Aliyu, O.M. and B.O. Makinde. 2016. Phenotypic analysis of seed yield and yield components in cowpea (Vigna unguiculata L., Walp). Plant Breed. Biotech. 4:252-261.

Arslan, C., B. Uzun, S. Ulger and M.I. Cagirgan. 2007. Determination of oil content and fatty acid composition of sesame mutants suited for intensive management conditions. J. Am. Oil Chem. Soc. 84:917-920.

Ashri A. 1988. Sesame breeding-objectives and approaches. In: Oil Crops-Sunflower, Linseed and Sesame. Proceedings of the 4th Oil Crops Network Workshop, Njoro, Kenya, January 1988, IDRC-MR205e. Ottawa: IDRC, pp. 152-164.

Ashri, A. 1989. Sesame. In: Oil Crops of the World: Their Breeding and Utilization, eds. Robbelen, G., Downey R.K. and Ashri A., 375-387, McGraw Hill Publ. Company.

Ashri, A. 2007. Sesame (Sesamum indicum L.). In: Genetics Resources, Chromosome Engineering and Crop Improvement, Oilseed Crops, Vol.4, ed. Singh R.J., 231-289, CRC Press, Boca Raton.

Baydar, H. 2005. Breeding for the improvement of the ideal plant type of sesame. Plant Breeding. 124:263-267.

Bisht I.S., K.V. Bhat, S. Lakhanpaul, B.K. Biswas, M. Pandiyan and R.R. Hanchinal. 2004. Broadening the genetic base of sesame (Sesamum indicum L.) through germplasm enhancement, Plant Genet. Resour. 2:143-151.

Bisht, I.S., R.K. Mahajan, T.R. Loknothan and R.C. Agrawal. 1998. Diversity in Indian sesame collection and stratification of germplasm accessions in different diversity groups. Genet. Resour. Crop Ev. 45:325-335.

Chowdhury, S., A.K. Datta, A. Saha, S. Sengupta, R. Paul, S. Maity and A. Das. 2010. Traits influencing yield in sesame (Sesamum indicum L.) and multi locational trials of yield parameters in some desirable plant types. Indian J. Sci. Technol. 3:163-166.

El-Bramawy, M.A.S. and W.I. Shaban. 2008. Inheritance of yield, yield components and resistance to major diseases in Sesamum indicum L. Span. J. Agric. Res. 6:623-628.

Erbas, M., H. Sekerci, S. Gul, S. Furat, E. Yol and B. Uzun. 2009. Changes in total antioxidant capacity of sesame (Sesamum sp.) by variety. Asian J. Chem. 21:5549-5555.

Falusi, O.A. and E.A. Salako. 2003. Inheritance studies in wild and cultivated 'Sesamum' L. species in Nigeria. J. Sustain. Agr. 22:75-80.

FAOSTAT. 2014. Faostat. FAO, Rome. http://faostat.fao.org/beta/en/\#data/QC. Accessed 26 Aug 2016.

Furat, S. and B. Uzun. 2010. The use of agro-morphological characters for the assessment of genetic diversity in sesame (Sesamum indicum L). Plant Omics. 3:85-91.

Gnanasekaran, M., S. Jebaraj and S. Muthuramu. 2008. Correlation and path co-efficient analysis in sesame (Sesamum indicum L.). Plant Archives. 8:167-169.

Langham, D.R. and T. Wiemers. 2002. Progress in mechanizing sesame in the US through breeding. In. Trends in New Crops and New Uses, eds. Janickand J. and Whipkey A., 157-173, American Society for Horticultural Science Press, Virginia.

Mahajan, R.K., I.S. Bisht and B.S. Dhillon. 2007. Establishment of a core collection of world sesame. (Sesamum indicum L.) germplasm accessions. Sabrao J. Breed. Genet. 39:53-64.

Ogbonna, P.E. and S.I. Ukaan. 2012. Yield evaluation of 13 sesame (Sesamum indicum L.) accessions in the derived savannah agro-ecology of south-eastern Nigeria. Afr. J. Agric. Res. 7:5772-5778.

Ozer, H., E. Oral and U. Dogru. 1999. Relationships between yield and yield components on currently improved spring rapeseed cultivars. Turk. J. Agric. For. 23:603-607.

Sarwar, G., M.A. Haq, M.B. Chaudhry and I. Rabbani. 2007. Evaluation of early and high yielding mutants of sesame (Sesamum indicum L.) for different genetic parameters. J. Agric. Res. 45:125-133. 
Sogut, T. 2009. Effect of main and second cropping on seed yield, oil and protein content of sesame (Sesamum indicum L.) genotypes. Turk. J. Field Crops 142:64-71.

Steel, R.G.D. and J.H. Torrie. 1980. Principles and procedures of statistics: A Biometrical Approach. McGraw-Hill, New York.

Strickberger, M.W. 1985. Genetics. 3.ed. W.H. Freeman, San Francisco.

Subramanian, S. and M. Subramanian. 1994. Correlation studies and path coefficient Analysis in sesame (Sesamum indicum L.). J. Agron. Crop Sci. 173:241-248.

Sumathi, P. and V. Muralidharan. 2010. Inheritance of branching and important biometrical traits in sesame (Sesamum indicum L.). Indian J. Genet. Plant Breed. 70:1-5.

Udensi, O. and E.V. Ikpeme. 2012. Correlation and path coefficient analyses of seed yield and its contributing traits in Cajanus cajan (L.) Millsp. American Journal of Experimental Agriculture. 2: 351-358.
Uzun, B., C. Arslan, M. Karhan and C. Toker. 2007. Fat and fatty acids of white lupin (Lupinus albus L.) in comparison to sesame (Sesamum indicum L.). Food Chem. 102:45-49.

Uzun, B., C. Arslan and S. Furat 2008. Variation in fatty acid compositions, oil content and oil yield in a germplasm collection of sesame (Sesamum indicum L.). J. Am. Oil Chem. Soc. 85:1135-1142.

Yol, E. and B. Uzun. 2012. Geographical patterns of sesame accessions grown under Mediterranean environmental conditions, and establishment of a core collection. Crop Sci. 52: 2206-2214.

Yol, E., E. Karaman, S. Furat and B. Uzun. 2010. Assessment of selection criteria in sesame by using correlation coefficients, path and factor analyses. Aust. J. Crop Sci. 4:598-602.

Yol, E., Furat, S. and B. Uzun. 2013. Genetic control of purple plant color in sesame. Turk. J. Field Crop. 18: 229-232. 